\title{
Effects of Dioxin Exposure on Thyroid Hormones of Populations Living in hot Spots of Dioxin Contamination in Vietnam
}

Tran Van Khoa, Dang Tien Truong, Nguyen Duy Bac, Pham The Tai, Le Bach Quang and Hoang Van Luong*

Biopharmaceutical medical research center, Vietnam Military Medical University, 222 Phung Hung Street, Ha Dong Districts, Hanoi, Vietnam

*Corresponding author: Luong HV, Vice Director of Vietnam Military Medical University, 222 Phung Hung Street, Ha Dong Districts, Hanoi, Vietnam, Tel: (84) 69566103; E-mail: luonghv@vmmu.edu.vn

Received date: July 24, 2015; Accepted date: August 17, 2015; Published date: August 25, 2015

Copyright: @ 2015 Khoa TV, et al. This is an open-access article distributed under the terms of the Creative Commons Attribution License, which permits unrestricted use, distribution, and reproduction in any medium, provided the original author and source are credited.

\begin{abstract}
Dioxin is still long persistent in environment. The effect of Dioxin on thyroid function is inconsistent. Da Nang and Bien Hoa airbases have been hot spots for persistent contamination since 1961. Inhabitant living around these sites has been exposed to dioxin for a long time. Serum dioxin level of people was much higher than those in other sites. This study evaluates serum dioxin level using DR CALUX and thyroid function including T3, T4, FT3, FT4, TSH measurement. T3 level was found association with serum dioxin level. There were not any relation between T4, FT3, FT4 and TSH and dioxin level.
\end{abstract}

\section{Keyword:}

Dioxin; Thyroid; Da Nang; Bien Hoa

\section{Introduction}

Dioxins [polychlorinated dibenzo-p-dioxins, dibenzofurans (PCDD/Fs)] are highly toxic environmental contaminants, which are lipophilic and resistant to biodegradation. These compounds enter the human body through the food chain and finally accumulate in adipose tissue [1]. A series of deleterious health effects are thought to be associated with dioxins exposure. From some studies on animal, as well as on some populations worldwide, dioxins were considered as endocrine disruptors, in which thyroid gland was one prominent target. In animal models, maternal exposure to TCDD induces elevated b-TSH and neonatal primary hypothyroidism. TCDD and other related compounds have been shown to accelerate thyroid hormone clearance by increasing metabolic enzyme activity and competing with plasma binding proteins [2-4]. The effects of dioxin on endocrine system may trigger other health outcomes such as infant growth retardation and developmental abnormalities, altered reproductive capacity $[2,3]$. Da Nang and Bien Hoa airbases were considered as hot spots of dioxin contamination in Vietnam. These former US airbases had served as sites for transportation and storage of great amount of herbicides for herbicide spraying program in southern Viet Nam that extended from 1962 to 1971. These two airbases were extremely contaminated with dioxins due to the tremendous amount of herbicide stored and spilled during mixing and loading there. Populations residing around these airbases were at high risk of exposure. Tai et al. [4] recently showed that levels of PCDDs/Fs in the breast milk of mothers residing near hot spots were threefold to fourfold higher than those in the breast milk of mothers living in unsprayed areas, and that infant daily dioxin intake (DDI) of Vietnamese infant in hot spots were estimated to be twofold to threefold higher than the recently documented values in US and Japanese infants [4]. In this study, we want to clarify the effects of dioxin exposure on thyroid function of general populations living in Da Nang and Bien Hoa airbases.

\section{Materials and Methods}

\section{Subject}

Subjects were recruited from general populations living around $\mathrm{Da}$ Nang and Bien Hoa airbases. In 2012, total 114 people, including 57 males and 57 females, were born before or during and after the period of herbicide spraying (1962-1971) participated in the survey. Demographic information of subjects was collected by an interview. A blood sample from each subject was collected in the morning of examination day. The serum was extracted from whole blood and store at $-20^{\circ} \mathrm{C}$ until analysis of hormones and dioxin levels.

We defined the body mass index (BMI) as weight $(\mathrm{kg})$ divided by the square of height $(\mathrm{m})$.

\section{T3, T4, FT3, FT4, TSH measurement}

The estimation of T3, T4, FT3, FT4, TSH were done by electrochemiluminance method on Roche Elecsys 2010 instrument, using Elecsys and cobas e analyzers kit, with guidelines for the reference ranges of serum TSH, T3, T4, FT4, FT3 were as 0.27-4.3 $\mu \mathrm{IU} / \mathrm{ml}, 1.27-3.07 \mathrm{nmol} / \mathrm{l}, 71.5-158 \mathrm{nmol} / \mathrm{l}, 12.7-20.8 \mathrm{pmol} / \mathrm{l}, 3.89-6.66$ $\mathrm{pmol} / \mathrm{l}$, respectively. For the analysis purpose, the values that were below detection limits were set as half of detection limit.

\section{Determine dioxin level in serum by DR CALUX}

The DR CALUX-bioassay analysis was performed in Dioxin laboratory of Vietnamese Military Medical University, which had been certified for approval to perform DR CALUX analysis by BioDetection System, Amsterdam, Netherlands. Approximately $2 \mathrm{ml}$ of serum was used for fat extraction by $\mathrm{n}$-hexane (Sigma) and 2-propanol (Merk). Fat content was weighted before clean-up step, in which acidlabile matrix components were removed by passage through a silica (Sigma) column containing two layers: $20 \%$ and $33 \%(\mathrm{w} / \mathrm{w})$ concentrated $\mathrm{H}_{2} \mathrm{SO}_{4}$ (Merk). This extract was dried and then diluted in dimethyl-sulphoxide (DMSO) (Sigma) before exposing to rat H4IIE hepatoma (H4L1.1c4) cells (BioDetection System, Holland). These 
Citation: Khoa TV, Truong DT, Bac NB, Tai PT, Quang LB, et al. (2015) Effects of Dioxin Exposure on Thyroid Hormones of Populations Living in hot Spots of Dioxin Contamination in Vietnam. Aging Sci 3: 141. doi:10.4172/2329-8847.1000141

Page 2 of 4

cells stably transfected with an AhR-controlled luciferase reporter gene construct (pGudluc1.1) and were grown confluent in 96-well view plates. Samples, TCDD standards (Bio-Detection System, Holland) and internal control were exposed in triplicate for 24 hours in the same plate, using DMSO $(0.8 \% \mathrm{v} / \mathrm{v})$ as a vehicle. After removal of the medium (Sigma), cells were washed twice with phosphate-buffered saline (Oxoid, Hampshire, UK). The cells were harvested in $30 \mu \mathrm{l}$ cell lysis reagent (Luciferase Assay System; Promega, Leiden, The Netherlands). For measurements of luciferase activity, $100 \mu$ luciferin assay mix at room temperature was added. After thorough mixing, the light production was measured in a Centro LB 960 Microplate Luminometer. A linear standard curve was built and used to calculate dioxin level in samples, which finally expressed in a pg unit of total bioanalytical equivalent (BEQ)/g fat.

Statistical analysis: we used median of Dioxin level (69.16 BEQ) as cut off to divide the subjects into two groups, high category and low category. In general analysis, data were expressed as frequency with percentage for categorical variables. For comparison of difference in percentage between groups, OR, CI, $\chi 2$ was performed. All comparisons were considered under a significance level 0.05. All data were analyzed using STATA version 12.0.

\section{Results}

\begin{tabular}{|c|c|c|c|}
\hline & High & Low & \multirow{2}{*}{ Total } \\
\hline & $>69.16 \mathrm{BEQ} / \mathrm{g}$ & $<69.16 \mathrm{BEQ} / \mathrm{g}$ & \\
\hline & $\mathrm{n}(\%)$ & $\mathrm{n}(\%)$ & $\mathrm{n}(\%)$ \\
\hline $\mathbf{n}$ & 57 & 57 & \\
\hline Mean BEQ & $106.38(35.34)$ & $38.67(18.4)$ & \\
\hline Range & $70.58-209.54$ & $5.40-67.75$ & \\
\hline \multicolumn{4}{|l|}{ Age group } \\
\hline $20-\leq 30$ & $2(50)$ & $2(50)$ & $4(100)$ \\
\hline $30-\leq 40$ & $3(50)$ & $3(50)$ & $6(100)$ \\
\hline $40-\leq 50$ & $16(48.8)$ & $17(51.52)$ & $13(100)$ \\
\hline $50-\leq 60$ & $26(54.17)$ & $22(45.83)$ & $48(100)$ \\
\hline$>60$ & $10(43.48)$ & $13(56.52)$ & $23(100)$ \\
\hline \multirow[t]{2}{*}{ Total } & $57(50)$ & $57(50)$ & $114(100)$ \\
\hline & \multicolumn{2}{|c|}{$p>0.05$} & \\
\hline \multicolumn{4}{|l|}{ Gender } \\
\hline Male & $25(43.86)$ & $32(56.14)$ & $57(100)$ \\
\hline Female & $32(56.14)$ & $25(43.86)$ & $57(100)$ \\
\hline \multirow[t]{2}{*}{ Total } & $57(100)$ & $57(100)$ & $114(100)$ \\
\hline & \multicolumn{2}{|c|}{$p>0.05$} & \\
\hline \multicolumn{4}{|l|}{ BMI } \\
\hline$<18.5$ & $4(6.25)$ & $4(8)$ & $8(7,01)$ \\
\hline $18.5-<25$ & $42(76.56)$ & $41(68)$ & $83(72.81)$ \\
\hline$\geq 25$ & $11(17.19)$ & $12(24)$ & $23(20,18)$ \\
\hline
\end{tabular}

\begin{tabular}{|l|l|l|l|}
\hline Total & $64(100)$ & $50(100)$ & $114(100)$ \\
\hline & \multicolumn{3}{|c|}{$p>0.05$} \\
\hline
\end{tabular}

Table 1: Demographic characteristics by BEQ category.

The subjects were divided into two groups basing on level of dioxins in serum blood. The cut-off value was set equal to absolute median of dioxin concentration (69.19pg BEQ/g fat). Demographic characteristics of the participants in both groups were presented in Table 1. Distribution of age, gender, BMI between high and low groups was not different $(\mathrm{p}>0.05)$. The mean dioxin level in high group was approximately 3 times higher than that in low group (106.38 vs $38.67 \mathrm{pg} \mathrm{BEQ} / \mathrm{g}$ fat).

Effect of Dioxin on thyroid function was showed in Table 2, number of abnormal of TSH, T3, T4, FT3, FT4 in High BEQ category were higher than that in Low category. But number abnormal of TSH, T4, FT3, and FT4 were not significantly difference between two groups. The odd ratios of all thyroid hormone exception of T3 did not increase or decrease significantly between groups. Odd ratio of T3 showed significant association between high category and low category $\left(\mathrm{OR}=2.407, \mathrm{CI}: 1.222-5.163, \chi^{2}=0,519, \mathrm{p}=0.023\right)$.

\begin{tabular}{|c|c|c|c|c|}
\hline & & High & Low & \multirow{2}{*}{ Total } \\
\hline & & $\begin{array}{l}>69.16 \\
\mathrm{BEQ} / \mathrm{g}\end{array}$ & $<69.16 \mathrm{BEQ} / \mathrm{g}$ & \\
\hline & & $\mathrm{n}(\%)$ & $\mathrm{n}(\%)$ & $\mathrm{n}(\%)$ \\
\hline \multirow[t]{4}{*}{ TSH } & Normal & $8(14.04 \%)$ & $10(17.54)$ & $\begin{array}{c}18 \\
(15.79)\end{array}$ \\
\hline & Abnormal & $49(85.96)$ & 47 (82.46) & $\begin{array}{c}96 \\
(84.21)\end{array}$ \\
\hline & Total & $57(100)$ & $57(100)$ & $114(100)$ \\
\hline & & \multicolumn{2}{|c|}{$\begin{array}{c}\mathrm{OR}=0.767,95 \% \mathrm{Cl}: 0.279-2.111, x 2=0.2639 \\
p=0.607\end{array}$} & \\
\hline \multirow[t]{4}{*}{ T3 } & Normal & $18(31.58 \%)$ & $30(52.63)$ & $\begin{array}{c}48 \\
(42.11)\end{array}$ \\
\hline & Abnormal & $39(68.42)$ & 27 (47.37) & $\begin{array}{c}66 \\
(57.37)\end{array}$ \\
\hline & Total & $57(100)$ & $57(100)$ & $114(100)$ \\
\hline & & \multicolumn{2}{|c|}{$\begin{array}{c}\text { OR=2.407, } 95 \text { Cl: } 1.222-5.163, x 2=0.519, \\
p=0.023\end{array}$} & \\
\hline \multirow[t]{4}{*}{ FT3 } & Normal & $25(43.86)$ & $32(56.14)$ & $57(50)$ \\
\hline & Abnormal & $32(56.14)$ & $25(43.86)$ & $57(50)$ \\
\hline & Total & $57(100)$ & 57 (100) & $114(100)$ \\
\hline & & \multicolumn{2}{|c|}{$\begin{array}{c}\mathrm{OR}=1.638,95 \% \mathrm{Cl}: 0.782-3.434, x 2=0.4298 \\
p=0.1898\end{array}$} & \\
\hline \multirow[t]{3}{*}{ T4 } & Normal & $16(28.07)$ & $18(31.58)$ & $\begin{array}{c}34 \\
(29.82)\end{array}$ \\
\hline & Abnormal & $41(71.93)$ & $39(68)$ & $\begin{array}{c}80 \\
(70.18)\end{array}$ \\
\hline & Total & $57(100)$ & $57(100)$ & $114(100)$ \\
\hline
\end{tabular}




\begin{tabular}{|c|c|c|c|c|}
\hline \multirow[b]{2}{*}{ FT4 } & \multirow[b]{2}{*}{ Normal } & \multicolumn{2}{|c|}{$\begin{array}{c}\mathrm{OR}=1.183,95 \% \mathrm{Cl}: 0.53-2.642, \mathrm{x} 2=0.0588 \\
\mathrm{p}=0.682\end{array}$} & \multirow[b]{2}{*}{$\begin{array}{c}15 \\
(13.16)\end{array}$} \\
\hline & & $7(12.28)$ & $8(14.04)$ & \\
\hline & Abnormal & $50(87.72)$ & $49(85.96)$ & $\begin{array}{c}99 \\
(86.84)\end{array}$ \\
\hline & Total & $57(100)$ & $57(100)$ & $114(100)$ \\
\hline & & \multicolumn{2}{|c|}{$\begin{array}{c}\text { OR=1.166, } 95 \% \text { Cl: } 0.393-3.462, x 2=0.0768, \\
p=0.782\end{array}$} & \\
\hline
\end{tabular}

Table 2: Abnormal thyroid hormone levels by BEQ category.

In this study, there were no different distributions of age, gender and BMI between the two groups. There was significant association between T3 and BEQ category (Table 2) OR=2.407.

\section{Discussions}

There has been doubt that the orange agent could increase the thyroid hormone clearance in animal models. The present study investigated the hypothesis that exposure to dioxins could associate with the dysfunctions in thyroid hormones in human by conducting a cohort study in Bien Hoa and Da Nang, Vietnam. Our findings in this study suggested that the dioxins could be associated with the dysfunction of thyroid hormone in terms of T3 plasma concentration, but not for TSH, FT3, T4 and FT4.

Some human studies have investigated associations between serum TCDD concentrations and thyroid hormone levels in adults, and results have been inconsistent. Ott et al. reported positive associations between T4 and whole-blood TCDD concentrations measured in 131 trichlorophenol production plant workers more than 45 years after an accidental exposure to TCDD. Chloracne status and TCDD levels estimated by back-extrapolation to the time of the accident were also positively associated with T4 levels. There were no associations with TSH [5]. Other studies have similar result: high serum TCDD concentrations ( $\geq 1,860 \mathrm{pg} / \mathrm{g}$ lipids) measured more than 15 years after the last exposure were associated with an elevated free T4 index among $2,7,8$ trichlorophenol plant workers relative to 257 referents with lower exposure (mean serum TCDD concentration $=7 \mathrm{pg} / \mathrm{g}$ lipids), although no clear exposure-response relationship was demonstrated. No association was found between TCDD and total T4 or TSH [6]. Result of the study in Australia show that back extrapolated serum TCDD concentrations (but not con-current levels) were negatively correlated with triiodothyronine T3 but not T4 [7]. In a large ( $n=1,009$ exposed and 1,429 referents) prospective study of US Air Force veterans who sprayed TCDD-contaminated Agent Orange in Vietnam between 1962 and 1971, Pavuk et al. reported positive associations between serum TCDD concentrations in 1982-1997 and concomitantly measured TSH levels (but not total T4 levels, free T4 index, or T\% uptake) [8]. Chevrier [3] reported an inverse association between serum TCDD concentrations measured shortly after the Seveso trichlorophenol plant explosion and total T4 (but not free T4, free T3, or TSH) levels measured approximately 20 (but not 30 ) years later among women who were premenarche at the time of the accident. However, the result showed no clear associations between 1996 serum TCDD concentrations and any 1996 or 2008 thyroid hormone measures, suggesting an effect of initial exposure rather than of later body burden [3].
Overall, results of studies that examined TCDD and thyroid function provide little and inconsistent evidence of long-term TCDD effects on the adult thyroid. Our result was not consistent with those of Ott who found increases in mean total T4 and TBG with TCDD levels [5], Chevrier [3] and Calvert [6]. However, we found that abnormal T3 level significant relation to high category that agreed with observation of Johnson on human [7].

The reasons why we observed the significant association between the risk of having thyroid dysfunction with T3 but not T4, FT4 and TSH were still not explained clearly in previous studies. Chevrier J. reported weak association between T3 and TCDD, with $\mathrm{p}=0.13$. There are a lot of cause effects of thyroid function and made differences between results of the studies. In this case, the models of previous studies only measurement toxicity of 17 congeners of Dioxin. The substances were part of contribution to TEF. In our study, TEF was measurement based on DR CALUX technique. It can estimate toxicity of all substance of dioxin and dioxin - like compounds, including PCDDs, PCDFs, PCBs. On the other hand, Pavuk [8] used cut-off point (94 ppt for low and high category) higher so much than that in our study, 69.16 BEQ/g (ppt). They might cause of difference among the results.

Although few data are available on TCDD's potential for thyroid hormone disruption in women, a number of studies of other polychlorinated dibenzodioxins, dibenzofurans, and biphenyls whose dioxin-like activity was evaluated using toxic equivalents (TEQs) have been conducted, with similarly inconsistent results [9-13].

A recent study on approximately 225,000 veterans of the Vietnam era found that those who served in Vietnam or were otherwise exposed to defoliants had a 2.5 -fold to threefold higher prevalence of the diagnosis of Graves' disease, compared to Veterans who served elsewhere [14] non-significant increase in mean total T4 and a significant increase in mean FTI was found in exposed US workers, but the risk of abnormally high FTI was not increased [6]. Some report dioxin decrease total T3 serum level. Another result see changes in total T3 and total T4 $[15,16]$. Meanwhile, other results did not show any effects of dioxin on thyroid function [17-19].

One of limitation of this study was the lack of a control cohort including people who lived in assumed unexposed areas. This drawback, however, could be mitigated by comparing the risk of having thyroid dysfunction between the groups of having low and high serum dioxin level. Furthermore, the serum dioxin levels served as a reliable measurement for the level of dioxin exposure. Thus, the validity of the study was still guaranteed.

In conclusion, the findings in our study indicated that the dioxins exposure was associated with thyroid functions in term of T3. Further studies with larger sample size, however, should be conducted to confirm the results.

\section{Acknowledgements}

The authors thank Mrs. Nguyen Thi Hien, President of VAVA Da Nang for their valuable help during field surveys; medical staff in the 17 Hospital in Da Nang and Medical staff in Public Health department of Bien Hoa city.

Funding sources was supported by Project from Ministry of Natural Resources and Environment. 
Citation: $\quad$ Khoa TV, Truong DT, Bac NB, Tai PT, Quang LB, et al. (2015) Effects of Dioxin Exposure on Thyroid Hormones of Populations Living in hot Spots of Dioxin Contamination in Vietnam. Aging Sci 3: 141. doi:10.4172/2329-8847.1000141

Page 4 of 4

\section{References}

1. Liem AK, Fürst P, Rappe C (2000) Exposure of populations to dioxins and related compounds. Food Addit Contam 17: 241-259.

2. Leijs MM, ten Tusscher GW, Olie K, van Teunenbroek T, van Aalderen WM, et al. (2012) Thyroid hormone metabolism and environmental chemical exposure. Environ Health 1: S10.

3. Chevrier J, Warner M, Gunier RB, Brambilla P, Eskenazi B, et al. (2014) Serum dioxin concentrations and thyroid hormone levels in the Seveso Women's Health Study. Am J Epidemiol 180: 490-498.

4. Tai PT, Nishijo M, Kido T, Nakagawa H, Maruzeni S, et al. (2011) Dioxin concentrations in breast milk of Vietnamese nursing mothers: a survey four decades after the herbicide spraying. Environ Sci Technol 45: $6625-6632$.

5. Ott MG, Zober A, Germann C (1994) Laboratory results for selected target organs in 138 individuals occupationally exposed to TCDD. Chemosphere 29: 2423-2437.

6. Calvert GM, Sweeney MH, Deddens J, Wall DK (1999) Evaluation of diabetes mellitus, serum glucose, and thyroid function among United States workers exposed to 2,3,7,8-tetrachlorodibenzo-p-dioxin. Occup Environ Med 56: 270-276

7. Johnson E, Shorter C, Bestervelt L, Patterson D, Needham L, et al. (2001) Serum hormone levels in humans with low serum concentrations of 2,3,7,8-TCDD. Toxicol Ind Health 17: 105-112.

8. Pavuk M, Schecter AJ, Akhtar FZ, Michalek JE (2003) Serum 2,3,7,8 tetrachlorodibenzo-p-dioxin (TCDD) levels and thyroid function in Air Force veterans of the Vietnam War. Ann Epidemiol 13: 335-343.

9. Foster WG, Holloway AC, Hughes CL Jr (2005) Dioxin-like activity and maternal thyroid hormone levels in second trimester maternal serum. Am J Obstet Gynecol 193: 1900-1907.

10. Wang SL, Su PH, Jong SB, Guo YL, Chou WL, et al. (2005) In utero exposure to dioxins and polychlorinated biphenyls and its relations to thyroid function and growth hormone in newborns. Environ Health Perspect 113: 1645-1650.
11. Chevrier J, Eskenazi B, Holland N, Bradman A, Barr DB (2008) Effects of exposure to polychlorinated biphenyls and organochlorine pesticides on thyroid function during pregnancy. Am J Epidemiol 168: 298-310.

12. Darnerud PO, Lignell S, Glynn A, Aune M, Törnkvist A, et al. (2010) POP levels in breast milk and maternal serum and thyroid hormone levels in mother-child pairs from Uppsala, Sweden. Environ Int 36: 180-187.

13. Turyk ME, Anderson HA, Persky VW (2007) Relationships of thyroid hormones with polychlorinated biphenyls, dioxins, furans, and DDE in adults. Environ Health Perspect 115: 1197-1203.

14. Spaulding SW (2011) The possible roles of environmental factors and the aryl hydrocarbon receptor in the prevalence of thyroid diseases in Vietnam era veterans. Curr Opin Endocrinol Diabetes Obes 18: 315-320.

15. Koopman-Esseboom C, Morse DC, Weisglas-Kuperus N, Lutkeschipholt IJ, Van der Paauw CG, et al. (1994) Effects of dioxins and polychlorinated biphenyls on thyroid hormone status of pregnant women and their infants. Pediatr Res 36: 468-73.

16. Schell LM, Gallo MV, Decaprio AP, Hubicki L, Denham M, et al. (2004) Thyroid function in relation to burden of PCBs, p,p'-DDE, HCB, mirex and lead among Akwesasne Mohawk youth: a preliminary study. Environ Toxicol Pharmacol 18: 91-99.

17. Longnecker MP, Ryan JJ, Gladen BC, Schecter AJ (2000) Correlations among human plasma levels of dioxin-like compounds and polychlorinated biphenyls (PCBs) and implications for epidemiologic studies. Arch Environ Health 55: 195-200.

18. Sala M, Sunyer J, Herrero C, To-Figueras J, Grimalt J (2001) Association between serum concentrations of hexachlorobenzene and polychlorobiphenyls with thyroid hormone and liver enzymes in a sample of the general population. Occup Environ Med 58: 172-177.

19. Seth A, Stanley S, Dhillo W, Murphy K, Ghatei M, et al. (2003) Effects of galanin-like peptide on food intake and the hypothalamo-pituitarythyroid axis. Neuroendocrinology 77: 125-131. 